\title{
Clinical Patterns and Psychiatric Comorbidity of Headache: A Study from Tertiary Hospital
}

\author{
Dr. Kodali Madhavi ${ }^{1 *}$, Dr. P.Krishna Mohan ${ }^{2}$, Dr. Sai kiran Pasupula ${ }^{3}$
}

\section{ABSTRACT}

Background: Headache is the most common medical disorder with a lifetime prevalence of over $90 \%$. Headache is commonly associated with psychiatric syndromes where psychiatrists are often consulted for the evaluation and treatment of people suffering from it. Aim: To study the clinical patterns and psychiatric co-morbidity of the patients suffering from headache attending to department of psychiatry in a general hospital. Methodology: After prior consent, Sociodemographic details and the clinical details of the headache were collected and the diagnosis of the headache was coded using ICHD. Psychiatric diagnosis was made using ICD-10 with the help of consultant. Results: Majority of the subjects (69.1\%) presented with primary headache. Tension type headache (49.1\%) was the most common type of headache followed by migraine (18.2\%). Secondary headaches were seen in $30.9 \%$ of individuals. Conclusion: Headache is commonly co-morbid with psychiatric disorders. Early identification of psychiatric disorders helps in proper management and treatment of the individuals with headache.

Keywords: Headache, Psychiatric disorders , Psychiatric comorbidity.

Headache is one of the most common complaints seen in patients attending psychiatric outpatient clinics. Prevalence of headache in general population during 1 year has been reported as about $46 \%$ with the life-time prevalence of $64 \% .{ }^{1}$ Recent studies on global burden of diseases identified tension type headache and migraine as the second and third most prevalent disorders worldwide. $^{2,3}$ Strong association has been established between primary headaches and psychiatric disorders. ${ }^{4}$ The overall prevalence of psychiatric disorders in patients with chronic daily headache was observed to be $66.1 \%{ }^{5}$ The most frequent being depressive and anxiety disorders. ${ }^{6}$ Psychiatric co-morbidity is associated with increased vulnerability and plays a significant role in the development of drug resistance as well as chronic primary headache, or vice versa, headache facilitating the psychiatric co-morbidity. ${ }^{7}$ Studies have shown that psychiatric comorbidity contributes to poor treatment outcomes in patients with headache ${ }^{8,9,10}$. Thus, understanding the clinical patterns of headache and its association with psychiatry

\footnotetext{
${ }^{1}$ M.D, Assistant Professor, Department of Psychiatry, Dr.PSIMS \& RF, Gannavaram, India

${ }^{2}$ M.D, Associate Professor, Department of Psychiatry, Dr.PSIMS \& RF, Gannavaram, India

${ }^{3}$ M.D, Senior resident, Department of Psychiatry, Guntur Medical college, Guntur, India

*Responding Author

(C) 2016 I K Madhvi, P Mohan, S Pasupula; licensee IJIP. This is an Open Access Research distributed under the terms of the Creative Commons Attribution License (http://creativecommons.org/licenses/by/2.0), which permits unrestricted use, distribution, and reproduction in any Medium, provided the original work is properly cited.
} 


\section{Clinical Patterns and Psychiatric Comorbidity of Headache: A Study from Tertiary Hospital}

disorders is important to provide integrated and effective treatment. In this above back ground the present study has been undertaken with the objective to study the clinical patterns of headache and psychiatric co-morbidity in the patients suffering from headache attending to the department of psychiatry.

\section{AIMS AND OBJECTIVES}

- To study the clinical patterns and psychiatric co-morbidity of the patients suffering from headache attending to department of psychiatry in a general hospital.

\section{METHODOLOGY}

This study was hospital-based cross sectional descriptive study. It was carried out at department of psychiatry of a tertiary care hospital, after obtaining approval from the Institution's ethical committee. The study sample consisted of 110 consecutive patients attending Psychiatry OPD with headache as a presenting complaint over a period of three months.

With prior consent, Socio-demographic details and the clinical details were taken. The diagnosis of headache type was made using International Headache Society-II (IHS-II) criteria ${ }^{11}$ and the diagnosis of psychiatric disorders was made using ICD-10. ${ }^{12}$ Statistical analysis was done by using Epiinfo and MS excel software's.

\section{ANALYSIS AND RESULTS}

Out of 110 subjects 65 (59\%) were females, 61 (55\%) were married, 68 (62\%) were literates, 63 (57\%) belonged to middle socioeconomic status. Mean age of the sample is 36.5 years. Majority of the sample is constituted by individuals from middle socioeconomic status (57\%). (Table 1)

\section{Table 1 : Socio-demographic Characteristics}

\begin{tabular}{|l|c|}
\hline Gender & n \\
\hline Male & 45 \\
Female & 65 \\
\hline Hindu & \\
\hline Christians & 75 \\
Muslims & 11 \\
& 24 \\
\hline
\end{tabular}




\begin{tabular}{|lc|}
\hline Education & 68 \\
\hline Literate & 42 \\
\hline Socio economic status & \\
\hline Low & 37 \\
Middle & 63 \\
High & 10 \\
\hline Marital status & 61 \\
\hline Married & 39 \\
\hline Unmarried & 19 \\
\hline Occupation & 32 \\
\hline Employed & 06 \\
\hline Unemployed & 53 \\
\hline Retired & \\
\hline Housewife & \\
\hline
\end{tabular}

Majority of the subjects (69.1\%) presented with primary headache. Tension type headache (49.1\%) was the most common type of headache followed by migraine (18.2\%). Secondary headaches were seen in $30.9 \%$ of individuals. (Table 2)

Table 2 : Type of Headache

\begin{tabular}{|l|l|}
\hline Type of headache & Percentage \\
\hline Tension type headache & $49.10 \%$ \\
\hline Migraine & $18.20 \%$ \\
\hline Other primary headaches & $1.80 \%$ \\
\hline Secondary headaches & $30.9 \%$ \\
\hline
\end{tabular}


The psychiatric comorbidity was observed in 70 (63.6\%) subjects. Among the individuals with psychiatric co morbidity majority were diagnosed with depressive disorder (60\%), followed by alcohol dependence syndrome (15.71\%), generalized anxiety disorder (14.28\%), panic disorder (8.57\%), and obsessive compulsive disorder (1.43\%).

\section{Figure 1: Break up of Psychiatry diagnosis}

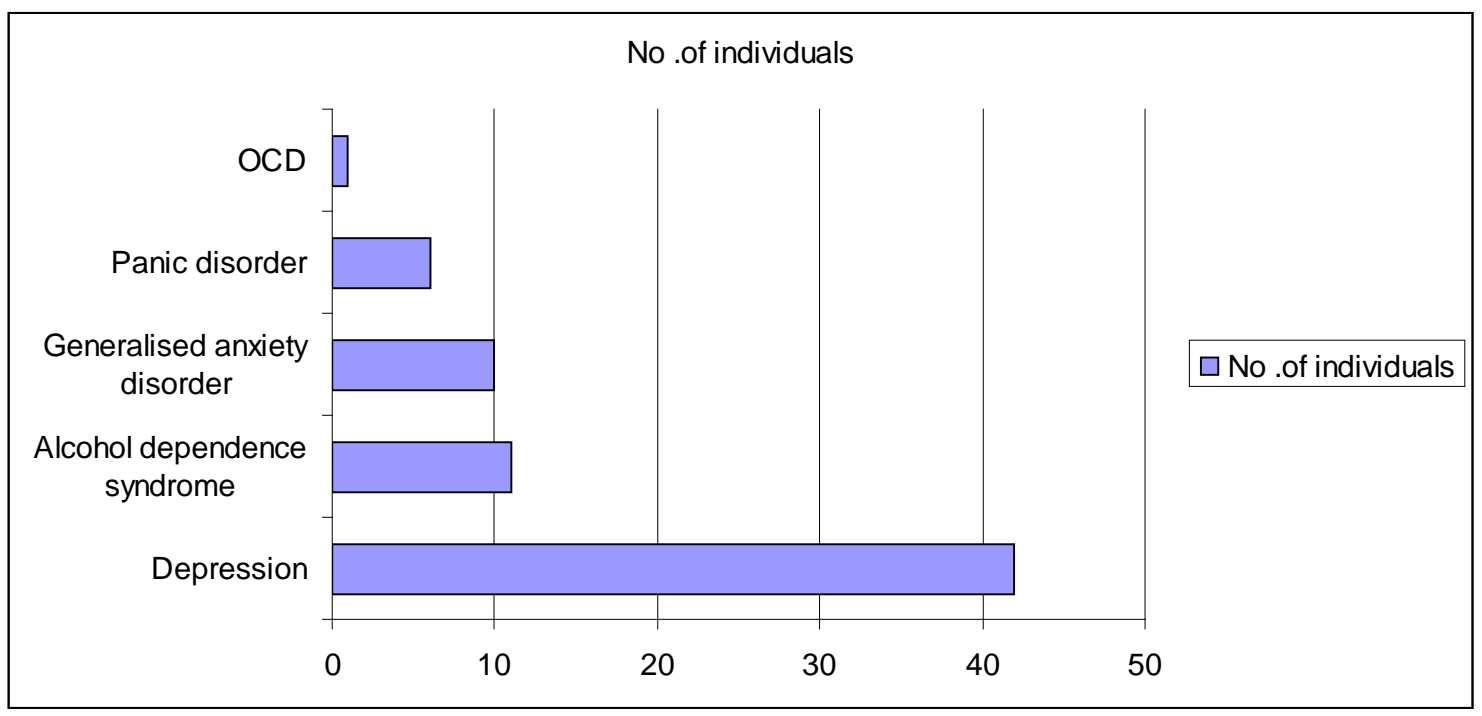

\section{DISCUSSION}

Mean age of the all participants is 36.5 years which supports the earlier studies that headache is more common among the middle aged individuals ${ }^{13}$. Females were over represented in many types of headaches ${ }^{13}$ and prescribing rates for headache are relatively high for women of middle age $^{14}$. The current study also found similar results.

Headache is a common somatic complaint by psychiatric patients ${ }^{15}$. It is observed in previous studies that major depressive disorder is more frequent psychiatric comorbidity in headache patients. ${ }^{16,17}$ The current study showed similar findings. Among the individuals with migraine most of them are diagnosed with depression which can be explained by migraine and major depressive disorder may be causally related, i.e. migraine may cause depression or conversely be caused by depression and more over migraine and major depressive disorder may share a common genetic and/or environmental pathophysiology . ${ }^{18,19}$ Depression and anxiety disorders are associated with headache through biological and mental pathways. ${ }^{7}$ The relation between primary headache and psychiatric disorders are bi-directional and headache triggers psychiatric disorders mostly of affective nature, and affects both their course and outcome. The association between mental disorders and headache is well established but the specificity to individual disorders is unclear. Most of the depressed patients suffered from headache ${ }^{20,21}$ and headache is also co-morbid with GAD, Panic disorder, somatoform disorder and $\mathrm{OCD}^{22}$. Patients who consult for headache experience severe disability and impact, and up to a third report anxiety 


\section{Clinical Patterns and Psychiatric Comorbidity of Headache: A Study from Tertiary Hospital}

and/or depression. ${ }^{23}$ Thus, identification of psychiatric comorbidity in headache patients helps in effective management of the condition.

However, this study has few limitations. Firstly, the sample size is small and sample constitutes of rural population, therefore cannot be extrapolated to a large sample and generalised to a general population. Secondly, cases those not referred to psychiatry department could not be included in the study as referral depends on the orientation of referring doctor but much care was taken with co-ordinating with other departments.

\section{CONCLUSION}

Headache is the most common presenting complaint and it is strongly associated with psychiatric disorders. Psychiatric comorbidity, especially depression is common in patients suffering with headache. Early identification of the psychiatric comorbidity in patients suffering with headache helps in integrated and effective management.

\section{REFERENCES}

1. Manzoni GC, Stovner LJ (2010) Epidemiology of headache. Handbook of Clinical Neurology 97:3-22

2. Vos T, Flaxman AD, Naghavi M, Lozano R, Michaud C, Ezzati M, et al. Years lived with disability (YLDs) for 1160 sequelae of 289 diseases and injuries 1990-2010: A systematic analysis for the Global Burden of Disease Study 2010. Lancet 2012;380:216396.

3. Steiner TJ, Stovner LJ, Birbeck GL. Migraine: The seventh disabler. Cephalalgia 2013;33:289-90.

4. Puca F. Psychological and social stressors and psychiatric comorbidity in patients with migraine without aura from headache centers in Italy: A comparison with tension-type headache patients. J Headache Pain 2000;1:17-25.

5. Puca F, Guazzelli M, Sciruicchio V, Libro G, Sarchielli P, Russo S, et al. Psychiatric disorders in chronic daily headache: Detection by means of the SCID interview. J Headache Pain 2000;1:Suppl: 33-7.

6. Verri AP, Projetti Cecchini A, Galli C, Granella F, Sandrini G, Nappi G. Psychiatric comorbidity in chronic daily headache. Cephalagia 1998;18 Suppl 21:45-9.

7. C. Gentili et al ., psychiatric comorbidity and chronicisation in primary headache ., J Headache Pain (2005) 6:338-340

8. Lake AE 3rd. Behavioral and nonpharmacologic treatments of headache. Med Clin North Am 2001;85:1055-75.

9. Lipchik GL, Rains J. Psychiatric and psychologic factors in headache. In: Loder E, Marcus DA, editors. Migraine in Women. Hamilton:Decker; 2004. p. 14 4-64.

10. Lipchik GL, Penzien DB. Psychiatric comorbidities in patients with headache. Sem Pain Med 2004;2:93-105. 


\section{Clinical Patterns and Psychiatric Comorbidity of Headache: A Study from Tertiary Hospital}

11. Headache Classification Subcommittee of The International Headache Society (2004) The International Classification of Headache Disorders: 2nd Edition. Cephalalgia 24: 9160.

12. World Health Organization (1993) The ICD-10 Classification of Mental and Behavioural Disorders Diagnostic Criteria for Research, Geneva.

13. Anke C. Winter et al., Association between lifestyle factors and headache., J Headache Pain (2011) 12:147-155 DOI 10.1007/s10194-010-0286-0

14. R Latinovic et al., Headache and migraine in primary care: consultation, prescription, and referral rates in a large population J Neurol Neurosurg Psychiatry 2006;77:385-387. doi: 10.1136/jnnp.2005.073221

15. S.Wang et al., EHMTI-0019. Exploratory research of headache from psychiatric opd patients via biofeedback., The Journal of Headache and Pain 2014, 15(Suppl 1):E40

16. Sheik Shoib, Raheel Mushtaq, Rayees Ahmed Sofi and Tasleem Arif. Recognising Risk Of Psychiatric Comorbidity in Headache: Looking for Symptoms of Anxiety and Depression in Headache: A Study from General Hospital in Kashmir (India). Journal Depresssion Anxiety (2014), S1:006

17. Himanshu Sharma and Savan Shah. Psychiatric comorbidity of Headache in a medical camp in rural area. Indian Journal of Psychiatry (2006); 48(3):185-188.

18. C. Majella Cahill and Kieran C. Murphy. Migraine: Another Headache For Psychiatrists? British Journal Of Psychiatry(2004);185:191-193

19. Zainab Samaan et al., Migraine in recurrent depression: case-control study ., The British Journal of Psychiatry (2009) ., 194, 350-354. doi: 10.1192/bjp.bp.108.054049

20. Gupta R , Bhatia M S, Singh P N, Upreti R. Association of depression with headache. Journal of Pakistan Psychiatry Society 2007; 4(2): 8

21. Belbase M1, et al .,Depressive disorder and its mental co-morbidity in patients attending psychiatry OPD at Nepalgunj Medical College, Kohalpur

22. Marlow A R , Kegowicz C L Starkey K N. Prevalence of depression symptoms in outpatients with a complaint of headache. J Am Board Fam Med 2009;22:633- 37.

23. Leone Ridsdale et al ., How do patients referred to neurologists for headache differ from those managed in primary care? British Journal of General Practice, May 2007

How to cite this article: K Madhvi, P Mohan, S Pasupula (2016), Clinical Patterns and Psychiatric Comorbidity of Headache: A Study from Tertiary Hospital, International Journal of Indian Psychology, Volume 3, Issue 3, No. 9, DIP: 18.01.169/20160303, ISBN: 978-1-36513820-1 